\title{
The Policy Implementation of the Inclusive Education at the Secondary Education Level in Palu City, Indonesia
}

\author{
Faizal $^{1 *} \quad$ Muhammad Basir $^{2} \quad$ Hasbullah $^{3} \quad$ Muhammad Nur Ali ${ }^{3} \quad$ Muhammad Khairil $^{3}$ \\ 1.Postgraduate students at Tadulako University, Indonesia \\ 2.Faculty of Agriculture, Tadulako University, Indonesia \\ 3.Faculty of Social and Political Sciences, Tadulako University, Indonesia
}

\begin{abstract}
This study aims to analyze how implementers understand the implementation of inclusive education at the level of secondary education in Palu City. This type of research is qualitative research. The Education and Culture Office of Central Sulawesi Province as an analysis unit for the implementation of inclusive education policies and the School for Providing Inclusive Education mostly understood the standards and targets and orientation of inclusive education, but in accepting students was limited to specific children with special needs, for example disabled, low vision, slow leaner and mild autism, while those who are blind or deaf are recommended to Special Education School. The pattern of communication developed in the implementation of inclusive education policies in the secondary education level in the city of Palu in Central Sulawesi Province involves various institutions such as: The Office of Education and Culture of Central Sulawesi Province in this case the PK-PLK Sector, Inclusive Organizing Schools, Special Education School and Higher Education. Forms of communication developed between institutions implementing inclusive education are formal, vertical and horizontal. The resource support, namely special tutor who has Special Education qualifications and resource space for children with special needs is not yet available, and there is no proportional budget available for schools implementing inclusive education. The contributions of the social environment are the school and the community response, especially parents provide the support. However, the economic aspect is that schools which provide the inclusive education are not supported by proportionally specific budgets. Political factors in the context of local politics, for example the elections, did not find any influence in the implementation of inclusive education policies.
\end{abstract}

Keywords: Policy of Implementation, Inclusive Education, Secondary education

DOI: $10.7176 /$ PPAR/10-4-06

Publication date: April $30^{\text {th }} 2020$

\section{Introduction}

Education for children with special needs in Indonesia is currently experiencing many fundamental changes as a consequence of the implementation of the inclusive education policies. The most important consequence of these changes is the recognition and appreciation for diversity. The regulations on the inclusive education have been included in several documents, namely: World Declaration on Educational for All, Jomtien, Thailand 1990, The Salamannca Statement and Framework for Action on Special Needs Education, Unesco 1994. which states that schools must accommodate children, regardless of physical conditions, intellectual, social, emotional, linguistic, and other conditions. Furthermore, the Dakar Framework for Action states that a child with a disability should attend school near his home together with other children (UNESCO, 2000).

Law No. 20 of 2003 concerning the National Education System, article 5, guarantees that every citizen has the same right to obtain quality education, including citizens who have physical, emotional, mental, intellectual and / or social disabilities are entitled to special education (Ministry of National Education Indonesia, 2007). Permendiknas No. 70 of 2009 Article 3, states that every student who has physical, emotional, mental, social, or potential intelligence and / or special talents has the right to participate in inclusive education at certain educational units according to their needs and abilities (Ministry of National Education Indonesia, 2009). Although the existence of inclusive education has gained a strong legal footing, in its implementation in Central Sulawesi Province, it still faces a number of obstacles. The inclusive organizing schools still lack teaching staff who have special education qualifications and competencies / Special Education. In some schools which provide the inclusive education, the existence of children with special needs, especially those who have physical, emotional, mental, and social neglect, are still faced with resistance. This shows that the inclusive education which is supposed to be the center of the growth of togetherness values, in practice is still often colored by conditions of inequality. The emergence of this resistance is mainly caused by the lack of understanding of school citizens and the community towards the philosophy of inclusive education. This is due to the lack of information and socialization about inclusive education (Ludago, 2020).

The success of the policy implementation depends on the ability to utilize available resources (Pradhan et al., 2017). Humans are the most important resource in determining the success of a policy implementation(Rajapakshe, 2018). Each stage of implementation requires quality human resources according to the work required by politically determined policies. The inclusive education is an education service system that requires children with 
special needs to learn in the nearest schools in the ordinary class with their peers. Inclusive Education is all children and young people, with and without disabilities or difficulties, learning together in ordinary pre-school provision, schools, colleges and universities with appropriate networks of support (Canestrari \& Marlowe, 2018). From the definition above asserted that inclusive education is intended as an education service system that includes children with special needs to learn together with their peers in the regular school closest to their place of residence. The implementation of inclusive education requires schools to make various adjustments namely curriculum and learning systems that are oriented to the needs of students, dynamic and constructive. Diversification of the curriculum is necessary given to the diversity of characteristics of students, as well as an active learning system that is friendly and fun tailored to the individual needs of students. Infrastructure is also needed in the form of accessibility, equipment, learning resources and learning media that are appropriate to the needs of students.

The philosophy that underlies the inclusive education is the belief that every child, both due to physical / mental development impairments and intelligent / special talents has the right to receive education like other "normal" children in the same environment. More broadly, this can be interpreted that children who are "normal" or those who are assessed as having special needs should be educated together in a diversity that include inclusive education which is expected to be one of the efforts to increase the participation of children with special needs in school and at the same time can improve the quality of education. Here, they are not merely pursuing academic ability, but more than that, they learn about life itself. In a broader context, inclusive education can also be interpreted as a form of education reform that emphasizes anti-discrimination attitudes, the struggle for equal rights and opportunities, justice, the expansion of access to education for all, and improving the quality of education (UNICEF, 2020). Furthermore, in the context of special education in Indonesia, inclusive education is not the only way to educate disabled children with a view to replacing segregation education but rather an alternative choice of innovation or new breakthroughs, in addition to segregation education that has been running for more than a century. This is because the setting of special education or special education in Indonesia adheres to the "Multitrack Approach" approach. It is just that the existence of an Extraordinary School which is supposed to be able to play a role as a resource center in supporting inclusion has not been maximally empowered. Although formally inclusive education in Indonesia has only been implemented in the last decade, it is believed that naturally inclusive education has been going on for a long time. This is inseparable from the philosophical, social, and cultural factors of Indonesia which highly value and uphold diversity or diversity. The advantage of inclusive education is that all children, including children with special needs, can interact naturally in accordance with the demands of daily life in the community, and their educational needs can be met according to their respective potential (Haddad, 2009). The consequence of implementing inclusive education is that schools are required to make various changes, starting from the perspective, attitude, to the educational process which is oriented towards individual needs without discrimination.

Based on the facts and preliminary observations of the implementation of inclusive education policy described above, it becomes the main reason and consideration that encourages researchers to conduct specific and in-depth research to find out what factors lead to the implementation of inclusive education policy at the secondary education level in Palu City has not shown the implementation performance as expected. The theory used as a reference or reference in this study is the theory of Van Meter and Van Horn public policy implementation, which emphasizes that the dimensions that influence policy implementation are: policy standards and objectives, resources, characteristics of implementing organizations, implementers' attitudes, communication, and social, economic and political environment (Meter \& Horn, 1975). Based on the facts revealed in the background above, this study aims to analyze how implementers understand the implementation of inclusive education at the level of secondary education in Palu City.

\section{Research Methods}

This research was conducted using a qualitative approach, carried out in Palu City, Central Sulawesi Province. Data collection techniques used were interviews, observation, and study of documents. Data analysis was carried out with the following stages: 1) Data reduction in this study will be conducted to select and sort data from interviews and observations to fit the data needs to answer the research problems that have been formulated, 2) Presentation of data in this study will be carried out after the data has been reduced, arranged systematically based on the type and pattern. Then the data is arranged in the form of narrative so as to form a meaningful series of information with the problem, 3) Drawing conclusions and verification. Verification will be carried out by finding new data that is more in-depth for conclusions. Conduct triangulation and discussion to check the validity of the data.

\section{Results and Discussion}

Policy Implementation of Inclusive Education for Secondary Education

1) Understanding of Implementers in the Implementation of Inclusive Education

The results of the study found the fact that in general the goals and objectives of the policy were already well- 
known by the policy implementer, in this case the education and culture department as an analysis unit and the school as an inclusive education organizing unit. It is interesting to explain further that the policy implementer and the school implementing inclusive education as the target that will be targeted as the policy implementation which are already well-aware of the standards and targets of inclusive education's policies, which aim are to provide access to wider and better education services in developing student expectations. It is also believed that through inclusive education it provides an optimal and excellent service to students and society as a whole which leads to improve the quality of education especially for children with special needs (Peters, 2003).

Although the standards and targets of inclusive education's policies are known, the implementers of inclusive education policies, in this case is the Office of Education and Culture of Central Sulawesi Province, are the analysis units of the implementation of inclusive education policies and at each school that organizes inclusive education that orientation is for the benefit of students with special needs or students in general to provide a better education without discrimination. It cannot be interpreted that the inclusive education policy has been implemented as a whole. Based on the field data that has been stated, some schools have not implemented consistently and thoroughly the inclusive education policies. Understanding and knowledge of the policies and schools which provides inclusive education, not only in the realm of standards and targets, but also to the level of providing education services in an inclusive setting as part of the standards and targets must be mastered by the implementer especially in the teaching staff and education personnel in schools which provide the inclusive education (Pappas et al., 2018). This understanding even reaches the level of implementation of classroom learning services, named inclusive education, which always leads to the emergence of recommendations on best practices in the service of children with special needs for the development and improvement of the quality of education through the formulation of programs in inclusive education.

2) Communication Patterns Developed

The policy implementation needs to be supported by good relations between the relevant agencies. This support is in the form of communication and coordination. Communication and coordination are important factors in implementing policies or implementing organizational programs so that organizational goals can be achieved well. (Khan, 2016) Specifically, it is said that if the organizations involved in implementing a policy coordinate well, the achievement of policy standards and objectives can be achieved effectively and efficiently.

From the results of the study, it was obtained that the implementation of inclusive education policies in the secondary education level in Palu City, Central Sulawesi Province, involved various institutions such as: the Office of Education and Culture in Central Sulawesi Province, in this case the PK-PLK sector as a lead sector, the human resources special tutors field, the high school sector, supervisors, inclusive education delivery schools and Special Education Schools. Other institutions that have an interest in implementing the implementation of inclusive education policies are tertiary institutions The form of communication developing between implementing institutions of inclusive education is to position the PK-PLK Field and inclusive education delivery schools as the axis of communication and coordination. Forms of communication developed are formal, vertical and horizontal. The formal form of communication and coordination developed by the PK-PLK Sector is when implementing inclusive education activities /programs communicating and coordinating with schools implementing inclusive education, special education schools and tertiary institutions. Specifically, coordination with tertiary institutions has been in the form of requests for information dissemination, technical guidance or workshops on inclusive education policy.

The dimensions of communication between organizations and strengthening activities are also related to the mechanism of communication between organizations in the policies implementation of inclusive education(Efendi, 2018). The communication and coordination mechanism is carried out in two approaches namely vertically and horizontally(Bartels et al., 2010). The vertical approach is carried out between the education office and the schools providing inclusive education while horizontally carried out between the inclusive educational delivery schools and special education schools. It is interesting to conduct further analysis related to the dimensions of communication and coordination of the implementation of inclusive education because structurally the strategic role of special education schools should be as a support center that will provide support for inclusive education provider schools, but the fact is that it does not work harmoniously so that the technical obstacles of children with special needs services and fulfillment of human resources special tutors with Special Education / Special Education qualifications faced by inclusive organizing schools can get a solution. This seems to be an empirical rational explanation for why the implementation of inclusive education policies has not been consistent, inclusive education organizing schools only accommodate certain children with special needs which are made possible by schools that are easy and capable of handling for example disabled, low vision, slow leaner and mild autistic, whereas for the blind or deaf recommended to Special Education School.

3) Resource Support

The success of policy implementation is highly dependent on the ability to use available resources or the ability to procure reliable resources to support inclusive education policies. Humans are the most important resource in determining the success of a policy implementation (Belyh, 2017). Each stage of implementation 
requires the availability of quality human resources in accordance with the work required by the policy. In addition to human resources, financial and time resources become important calculations in the successful implementation of policies. The results showed that with regard to human resources, it was found that the resources namely human resources special tutors were still lacking specifically related to human resources special tutors with special educational qualifications, as required by the inclusive education policy.

Budget resources owned by the Education and Culture Office of Central Sulawesi Province can be said to be still limited when compared to the number of schools providing inclusive education. So that in practice the Department of Education and Culture of Central Sulawesi Province is indeed still unable to provide assistance to all schools that have been appointed to carry out inclusive education programs adequately. This certainly affects the smooth implementation of inclusive education services in Central Sulawesi Province. The government through the education and culture service has indeed provided assistance in the form of facilities and infrastructure as well as other learning support tools, but even then it is still very limited, because the available funds are also very limited, so the implementation of inclusive education services is still very dependent on internal funding sources owned by each school. This is certainly still a bit burdensome for the organizing schools, because the budget owned by each school is certainly different from each other.

In the aspect of facility resources, there are still some obstacles encountered including the unequal quantity and quality of facilities and infrastructure owned by each school providing inclusive education (Wibowo \& Muin, 2018). This can be seen from schools that do not yet have complete and appropriate standard facilities and infrastructure. One example is the existence of schools that still do not have resource space and accessibility for students with special needs. For other facilities and infrastructure in the form of learning support tools for students with special needs in inclusive organizing schools, it can be said to be sufficient. The distribution of assistance provided by the Central Sulawesi Provincial Education Office has gone through an evaluation process for all existing inclusive schools. Through this evaluation the education office can arrange priority scales regarding which schools are eligible to receive assistance each year, so that the distribution can be done effectively and on target.

The most important human resource in the implementation of inclusive education policy besides human resources special tutors is the principal because the principal also acts as the implementing unit for inclusive education policy in the education unit. Therefore, the principal is not only required to master the management of policy implementation, but must also master the concept inclusive education and the philosophy of inclusive education in its entirety ranging from understanding of standards and targets to the ability to implement inclusive education policies (Hornby, 2015). The problem of resources that arise related to the implementation of inclusive education education policy is the limitations of special supervisors with the required qualifications and competencies. and funds or finance because there is no specific funding allocation for the implementation of inclusive education policies, there is no special BOS fund for inclusive schools.

4) Social, political and economic environmental conditions

There are three aspects which cover in the fifth dimension of Van Meter and Van Horn namely; social, economic and political environment. The environment here can be interpreted as social conditions, economic conditions, and political conditions (Meter \& Horn, 1975). These three elements everywhere always have an impact on human life. So, in terms of commonsense (rational-common sense) is very logical if this dimension impacts on policy implementation. The more conducive social, economic and political environment, the more potential to implement inclusive education policies effectively and efficiently. Conversely, the more problematic or disrupted social, economic and political conditions, the implementation of inclusive education policies also has the potential to experience obstacles. Based on data collection that has been done in the field, it is found that some social conditions are quite positive influencing the implementation of inclusive education policies, such as social relations between school residents not experiencing disturbances, they well come to children with special needs, they learn together. Other social conditions that influence the implementation of education policies inclusive are a relationship between teachers and students with special needs and is fully supportive. So that learning activities can run well. Including support from school residents.

Likewise, the response of the community itself is quite positive because the community which feels the benefits of a policy, of course, will provide support. The economic sub-dimension condition is also considered as a potential element that influences the implementation of inclusive education policies. In the analysis section on resources, it has actually been assessed that economic factors or funds are very influential on the implementation of inclusive education policies. Proportional budget support is one of the factors that strengthens the implementation of inclusive education policies. With regard to political factors in some areas with local political factors are dominant in affecting psychologically school principals and teachers. The dynamics that occur in several regions after each election. There are mutations of teachers, principals, or structural positions. However, this phenomenon is not quality in the context of schools that provides inclusion education for hammer secondary education. This means that political factors have no impact on the policies implementation of inclusive education. Likewise, the dynamics of interaction between school members in political content were also not found in this study 


\section{Conclusion}

Based on the formulation of the problem, the results of the research and discussion carried out in the previous chapter, some conclusions can be drawn as follows:

1) The Office of Education and Culture of Central Sulawesi Province as an analysis unit for the policies implementation of inclusive education and the School for Providing Inclusive Education mostly understands the standards and targets and also the orientation of inclusive education is in the interests of students with special needs and students in general, namely providing better education without discrimination and comprehensive education needs. However, in accepting students, it is limited to specific children with special needs which is possible for schools that are easy and able to handle for example disabled, low vision, slow leaner and mild autism, while for the blind or deaf people are recommended to Special education schools.

2) The pattern of communication developed in the implementation of inclusive education policies in the secondary education level in Palu City, Central Sulawesi Province, involves various institutions such as: the Office of Education and Culture in Central Sulawesi Province, in this case the PK-PLK Sector as a lead sector, the GTK field, the high school sector, supervisors, inclusive organizing schools, special education schools and universities. The form of communication developed between implementing institutions of inclusive education is formal, vertical and horizontal by positioning the PK-PLK Field and inclusive education delivery schools as the axis of communication and coordination.

3) The implementation of inclusive education policies at the secondary education level Palu City of Central Sulawesi Province has not been able to be implemented optimally. The ineffectiveness of the implementation of the inclusive education policy for the secondary education level in Palu City is due to the limited support of resources such as the unavailability of human resources special tutors with the required qualifications and resource space for children with special needs, and the unavailability of proportional special budgets for inclusive education provider schools.

4) Environmental contribution in the context of the social environment, inclusive organizing schools provide support as well as community response, especially parents also provide support. With regard to economics that schools implementing inclusive education are not supported by a special budget proportionately in implementing inclusive education policies. Political factors in the context of local politics, for example the elections, did not find any influence in the implementation of inclusive education policies. Likewise, the dynamics of interaction between school members in political content is also not found in this study

Recommendations:

1) Schools providing inclusive education are advised to accommodate all children with special need students, not just limited to specific children with special need, (low vision, slow leaner and mild autism) in line with the required human resources.

2) To optimize the policies implementation of inclusive education, the Central Sulawesi Province Office of Education and Culture is advised to submit to the regional government in this case the Regional Personnel Board for the formation of educators with Special Education qualifications for schools providing inclusive education.

3) Schools providing inclusive education at the secondary education level are advised to submit to the Central Sulawesi Province Education and Culture Office a special budget allocation with a proportional amount to optimize the implementation of inclusive education.

\section{References}

Bartels, J., Peters, O., de Jong, M., Pruyn, A., \& van der Molen, M. (2010). Horizontal and vertical communication as determinants of professional and organisational identification. Personnel Review, 39(2), 210-226. https://doi.org/10.1108/00483481011017426

Belyh, A. (2017, February 24). Essential Steps to a Successful Strategy Implementation Process. Cleverism. https://www.cleverism.com/strategy-implementation-process/

Canestrari, A. S., \& Marlowe, B. A. (2018). The Wiley International Handbook of Educational Foundations. John Wiley \& Sons.

Efendi, M. (2018). The Implementation of Inclusive Education in Indonesia for Children with Special Needs: Expectation and Reality. Journal of ICSAR, 2(2), 142-147. https://doi.org/10.17977/um005v2i22018p142

Haddad, C. (2009). Teaching children with disabilities in inclusive settings. UNESCO.

Hornby, G. (2015). Inclusive special education: Development of a new theory for the education of children with special educational needs and disabilities: Inclusive Special Education. British Journal of Special Education, 42(3), 234-256. https://doi.org/10.1111/1467-8578.12101

Khan, A. (2016). Policy Implementation: Some Aspects and Issues. Journal of Community Positive Practices, $X V I(3), 3-12$.

Ludago, T. B. (2020). Practices, Challenges and Opportunities of Inclusive Education Implementation in Kambata Tambaro Zone, Ethiopia. Open Access Library Journal, 07(02), 1. https://doi.org/10.4236/oalib.1105989 
Meter, D. S. V., \& Horn, C. E. V. (1975). The Policy Implementation Process: A Conceptual Framework. Administration \& Society, 6(4). https://doi.org/10.1177/009539977500600404

Ministry of National Education Indonesia. (2007). Act of the Republic of Indonesia, number 20, year 2003, on national education system. https://planipolis.iiep.unesco.org/en/2007/act-republic-indonesia-number-20year-2003-national-education-system-4216

Ministry of National Education Indonesia. (2009). Permendiknas Number 70 of 2009 Concerning Inclusive Education.

Pappas, M., Papoutsi, C., \& Drigas, A. (2018). Policies, Practices, and Attitudes toward Inclusive Education: The Case of Greece. Social Sciences, 7. https://doi.org/10.3390/socsci7060090

Peters, S. (2003). Inclusive education: Achieving education for all by including those with disabilities and special education needs.

Pradhan, N. S., Su, Y., Fu, Y., Zhang, L., \& Yang, Y. (2017). Analyzing the Effectiveness of Policy Implementation at the Local Level: A Case Study of Management of the 2009-2010 Drought in Yunnan Province, China. International Journal of Disaster Risk Science, 8(1), 64-77. https://doi.org/10.1007/s13753017-0118-9

Rajapakshe, W. (2018). Factors Affecting Human Resources Management Policy Implementation in Small and Medium Enterprises (SMEs) in Sri Lanka. International Journal of Academic Research in Business and Social Sciences, 7(12). https://doi.org/10.6007/IJARBSS/v7-i12/3744

UNESCO. (2000). The Dakar Framework for Action: Education for All: Meeting our collective commitments (including six regional frameworks for action)-UNESCO Digital Library. https://unesdoc.unesco.org/ark:/48223/pf0000121147

UNICEF. (2020). Inclusive Education, Antidiscrimination and Violence Prevention (Ref. Number: VN 8-529870). Uniced.

Wibowo, S. B., \& Muin, J. A. (2018). Inclusive Education in Indonesia: Equality Education Access for Disabilities. KnE Social Sciences, 3(5), 484. https://doi.org/10.18502/kss.v3i5.2351 